\title{
Anatomical variations of the carpal tunnel structures
}

\author{
Ryan Mitchell MD ${ }^{1}$, Amy Chesney MD², Shane Seal MD FRCSC ${ }^{3}$, Leslie McKnight MSc ${ }^{2}$, \\ Achilleas Thoma MD MSc FRCSC FACS ${ }^{2,4}$
}

R Mitchell, A Chesney, S Seal, L McKnight, A Thoma. Anatomical variations of the carpal tunnel structures. Can J Plast Surg 2009;17(3):e3-e7.

There are many anatomical variations in and around the carpal tunnel that affect the nerves, tendons and arteries in this area. Awareness of these variations is important both during the clinical examination and during carpal tunnel release. The purpose of the present review is to highlight recognized anatomical variations within the carpal tunnel including variation in nerve anatomy, tendon anatomical variants, vascular anatomical variations and muscle anatomical variations.

Key Words: Anatomical variations; Carpal tunnel; Carpal tunnel release; Median nerve; Ulnar nerve

\section{Variations anatomiques des structures du canal carpien}

L'anatomie des nerfs, des tendons et des artères situés dans le canal carpien ou autour de celui-ci connaît de nombreuses variations. Il est important de connaitre l'existence de ces variations à l'examen clinique et durant la libération du nerf médian à la hauteur du canal carpien. Le présent article a pour but de faire ressortir des variations anatomiques reconnues des structures du canal carpien, notamment celles touchant les nerfs, les tendons, les vaisseaux sanguins et les muscles.

\begin{abstract}
A surgeon's expert competency should include an appreciation of anatomical variations, particularly with respect to common surgical procedures. One such procedure where this is relevant to plastic surgeons is the carpal tunnel release. The carpal tunnel has been recognized as a site where multiple anatomical variations can occur. These variations can involve neural, vascular, tendinous and muscular structures. If these are unrecognized, there is a risk of iatrogenic injury to the involved structures leading to unfavourable surgical outcomes. The purpose of the present review is to highlight recognized anatomical variations within the carpal tunnel and, hopefully, to help practitioners perform safe surgery.
\end{abstract}

\section{THE CARPAL TUNNEL}

The carpal tunnel is defined as the space deep to the transverse carpal ligament. The transverse carpal ligament extends ulnarly from the hook of hamate and the triquetrum to the scaphoid and the trapezium radially. The carpal tunnel is bordered posteriorly by the carpal bones. Within the carpal tunnel lie the median nerve and nine flexor tendons: the flexor digitorum profundus (FDP) and flexor digitorum superficialis (FDS) tendons to the index, middle, ring and small fingers, as well as the flexor pollicis longus (FPL) tendon. A review of the literature identified variations in the structure within and around the carpal tunnel (Table 1).

\section{VARIATION IN NERVE ANATOMY}

\section{High bifurcation of the median nerve}

In most subjects, the median nerve courses through the carpal tunnel as a single nerve, dividing to form the digital nerves distal to the transverse carpal ligament. Bifurcation of the

\section{TABLE 1}

Anatomical anomalies within and around the carpal tunnel

Nerve anomalies

High bifurcation of median nerve

Aberrant origin of motor branch of median nerve

Transligamentous palmar cutaneous branch of median nerve

Anomalous course of ulnar nerve

Ulnar-to-median nerve connection (Marinacci communication)

Tendon anomalies

Conjoint FPL and FDP II (Linburg-Comstock syndrome)

Vascular anomalies

Persistent median artery

Superficial ulnar artery

Muscle anomalies

Palmaris longus

Index lumbrical

Flexor digitorum superficialis indicis

FDP Flexor digitorum profundus; FPL Flexor pollicis longus

median nerve proximal to the transverse carpal ligament is a relatively common anatomical variation present in $1 \%$ to $3.3 \%$ of individuals undergoing carpal tunnel release surgery (Figure 1) (1-3). High bifurcation of the median nerve can be an isolated finding (7) or it can be associated with a persistent median artery (4) or an accessory muscle belly of the long finger flexor superficialis $(1,5,6)$. A case of a bifid median nerve wherein the radial-sided branch was located in its own compartment within the carpal tunnel has been identified by the senior author (AT) (Figure 2). To our knowledge, this is the first report of this variation. This additional compartment was also released with satisfactory outcome.

${ }^{1}$ Division of Plastic Surgery, University of Manitoba, Winnipeg, Manitoba; ${ }^{2}$ Division of Plastic Surgery, McMaster University, Hamilton, Ontario; ${ }^{3}$ Division of Plastic surgery, University of British Columbia, Vancouver, British Columbia; ${ }^{4}$ Department of Clinical Epidemiology, McMaster University, Hamilton, Ontario

Correspondence: Dr Achilles Thoma, 206 James Street South, Suite 101, Hamilton, Ontario L8P 3A9. Telephone 905-523-0019, e-mail athoma@mcmaster.ca 


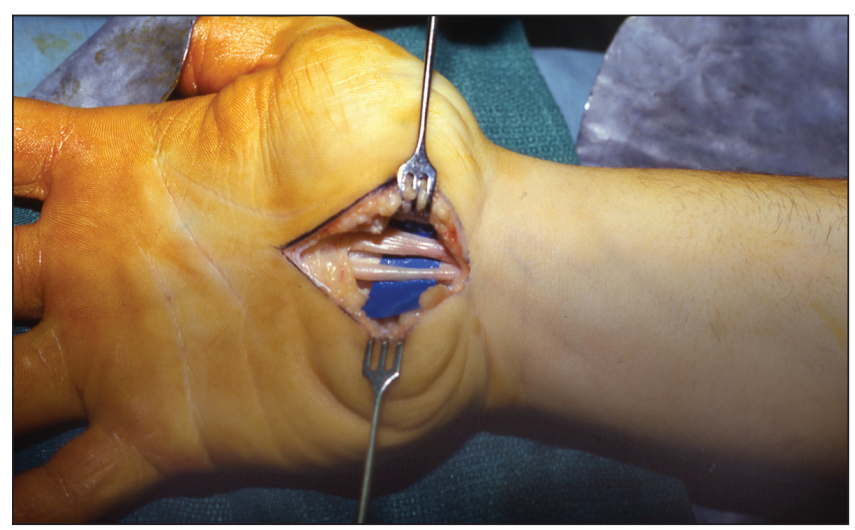

Figure 1) A 23-year-old man with a bifid median nerve identified at time of carpal tunnel release. No other anomalies were noted

Variations of the motor branch of the median nerve

The median nerve provides motor innervation to the first and second lumbricals, opponens pollicis, abductor pollicis brevis, and the superficial head of the flexor pollicis brevis. Anatomical variations involving the takeoff of the median nerve motor branch (recurrent branch) were first described by Lanz in 1977 (2). He classified these findings into three groups. The first and most common is an extra-ligamentous takeoff. It occurs in $46 \%$ to $90 \%$ of subjects and, due to its high prevalence, it is considered normal anatomy. In this case, the motor branch arises from the median nerve distal to the transverse carpal ligament on the radial side (Figure 3A). The second most common variation, occurring in approximately one-third of subjects, is a subligamentous takeoff. Here, the motor branch arises within the carpal tunnel (Figure 3B). The third variation in the motor branch, occurring in approximately one-quarter of subjects, is a trans-ligamentous takeoff. In this case, the motor branch pierces the transverse carpal ligament on its course toward the thenar musculature (Figure 3C). A rare fourth variation has been reported where the motor branch takes off from an ulnar and anterior location, bridging the median nerve as it approaches the thenar musculature (Figure 3D) (8). Finally, the motor branch may have a course superficial to the transverse carpal ligament, a variation found in $9 \%$ of patients undergoing carpal tunnel release surgery (Figure 3E) (9). Awareness of these variation can prevent injury to the recurrent motor branch.

Variations of the palmar cutaneous branch of the median nerve The palmar cutaneous branch of the median nerve arises from the radial border of the median nerve $5 \mathrm{~cm}$ to $6 \mathrm{~cm}$ proximal to the transverse wrist crease. As the palmar cutaneous branch traverses the wrist, it remains superficial to the transverse carpal ligament, passing between the superficial and deep layers of forearm fascia. It later divides into three terminal branches supplying the dermis. Two variations in the course of the palmar cutaneous branch have been described $(1,10)$. In the first, the nerve has a trans-ligamentous course piercing the transverse carpal ligament. In the second variant, the palmar cutaneous branch courses ulnar to the median nerve. These variations are important during carpal tunnel release surgery because injury to the palmar cutaneous nerve or its branches may result in development of a painful neuroma.

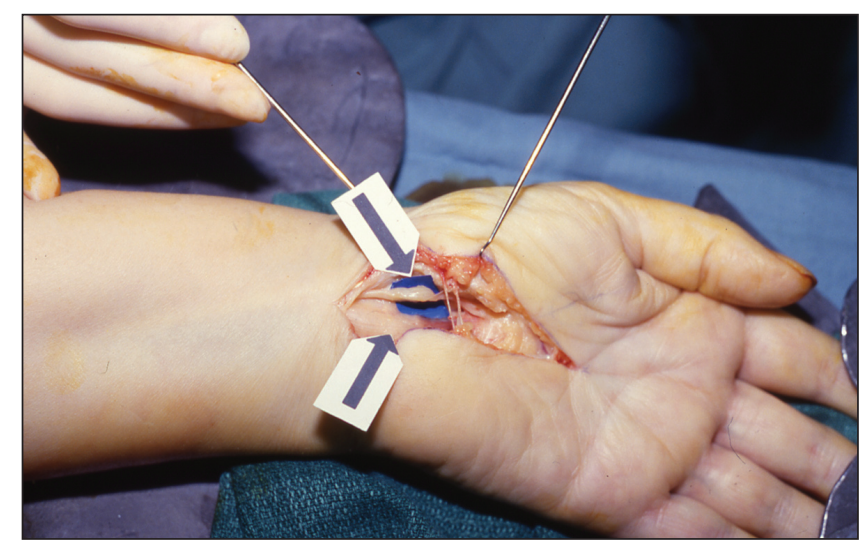

Figure 2) A 57-year-old woman with a bifid median nerve. The radial median nerve had its own compartment within the carpal tunnel that required separate release. The arrows show the two distinct branches

\section{Variations of the ulnar nerve}

The ulnar nerve courses along the forearm into Guyon's canal, a depression between the pisiform bone and the hook of the hamate, to provide both sensory and motor innervation to the hand. On rare occasions, the ulnar nerve has been found to lie within the carpal tunnel, as described in three case reports of patients undergoing carpal tunnel release surgery (11-13). These patients presented with carpal tunnel syndrome associated with symptoms of ulnar nerve compression including intrinsic muscle wasting and paresthesia involving the little finger and the ulnar half of the ring finger.

\section{Martin-Gruber and Marinacci communications}

An anomalous connection, commonly known as a MartinGruber anastomosis, may occur between the median and ulnar nerve in the forearm, resulting in varied patterns of innervation to the intrinsic muscles of the hand (14-20). The MartinGruber anastomosis is median to ulnar in nature (21). It has been reported to affect $6 \%$ to $31 \%$ of the population (22). The Marinacci communication, also known as a reverse MartinGruber anastomosis, is a rare condition in which the communicating nerve fibres run from the ulnar nerve to the median nerve. In a case report by Stancic et al (22), this connection was identified in the distal forearm during release of the carpal tunnel via an extended incision. To date, there have only been four published cases of Marinacci communication (22-25).

\section{TENDON ANATOMICAL VARIANTS}

\section{Linburg-Comstock syndrome}

The FPL tendon is typically independent from the FDP and FDS tendons. These muscles, however, are derived from a common mesodermal mass (26) and a tendinous connection can exist between them (Figure 4). In 1979, Linburg and Comstock (27) reported a tendinous connection between the FDP tendon of the index finger and the FPL tendon. They examined 194 patients and found this anatomical abnormality to be present unilaterally in 31\% and bilaterally in $14 \%$. A cadaver study by the same authors found that the tendinous connection was present unilaterally in $25 \%$ of subjects and bilaterally in $6 \%$ (28). Numerous case reports have also presented patients with this variant (29-31). In a case report by Slater (32), an 


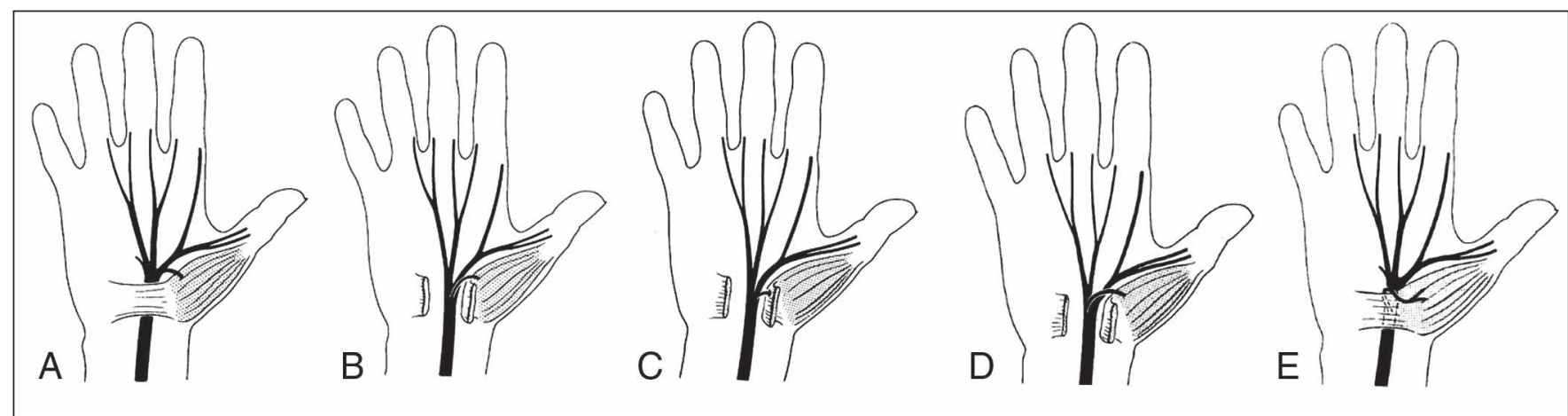

Figure 3) Variations in the takeoff of the median nerve motor branch. A Normal anatomy of the median nerve motor branch: extraligamentous and recurrent pattern. B Variation of the median nerve motor branch: subligamentous pattern. C Variation of the median nerve motor branch: transligmentous course. D Variation of the median nerve motor branch: ulnar takeoff. E Variation of the median nerve motor branch: superficial course. Reproduced from reference 2 with permission

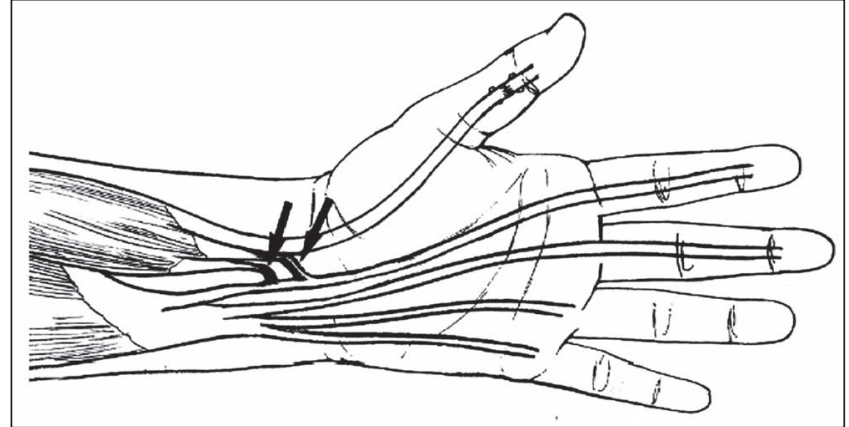

Figure 4) Linburg-Comstock syndrome: Anomalous tendon slips from the flexor pollicis longus to the flexor digitorum profundus resulting in an inability to actively flex the interphalangeal joint of the thumb without simultaneously flexing the distal interphalangeal joint of the index finger. Reproduced from reference 29 with permission

anomalous tendinous connection existed between the FPL and the FDP tendons to the index and middle fingers. Upon examination, patients with Linberg-Comstock sydrome are unable to actively flex the interphalangeal joint of the thumb without concomitant flexion of the distal interphalangeal joint of the index finger. This anomalous tendinous connection is rarely problematic, but may mimic symptoms of carpal tunnel syndrome through the development of symptomatic tendonitis.

\section{VASCULAR ANATOMICAL VARIATIONS}

\section{Persistent median artery}

The median artery is an embryological remnant that is present in $1.2 \%$ to $23 \%$ of the population $(33,34)$. It develops from the axillary artery and usually regresses in the second embryonic month. Barfred et al (35) reported nine patients in whom a persistent median artery was noted within the carpal tunnel at the time of carpal tunnel release. Since this report, smaller case series (33) and case reports $(36,37)$ have been published. A persistent median artery is generally asymptomatic and, in some cases, can contribute significantly to perfusion of the hand (38). As noted previously, it may be present in association with a bifurcated median nerve. The median artery has been reported to have a superficial course as it approaches the transverse carpal ligament, putting it at risk during carpal tunnel release (37).

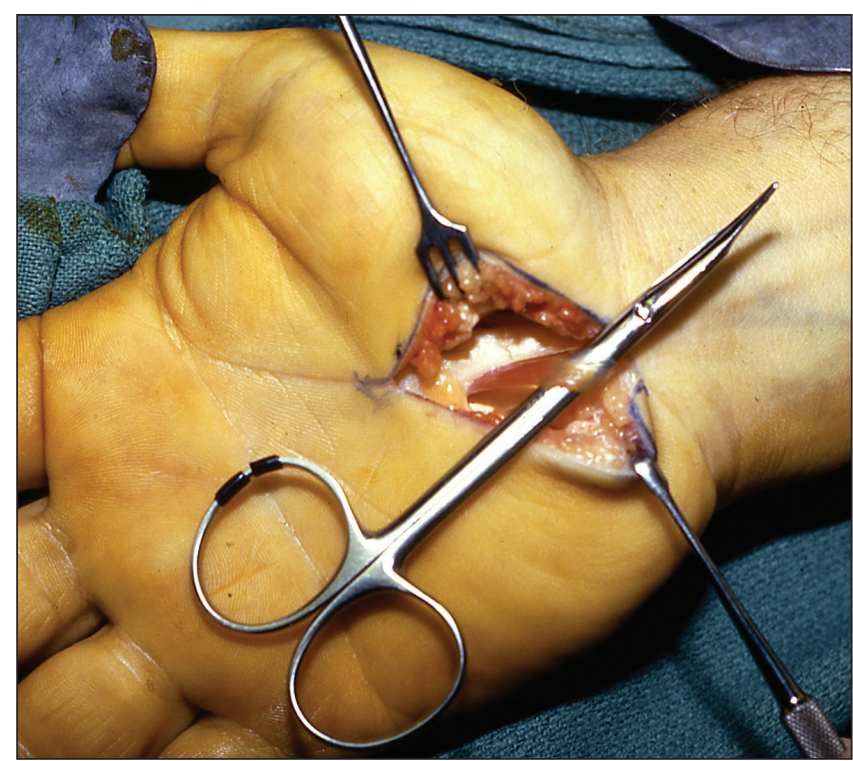

Figure 5) An anomalous palmaris longus tendon was noted to pass through the carpal tunnel and insert into the palmar aponeurosis. It has been transected proximally and is held by a clamp

\section{Superficial ulnar artery}

The ulnar artery is a terminal branch of the brachial artery. It travels along the ulnar side of the forearm under the flexor carpi ulnaris muscle. The ulnar artery may take a superficial course within the forearm, traveling superficial to the muscles but deep to the antibrachial fascia (Figure 5). The prevalence of a superficial ulnar artery has been reported to be between $0.7 \%$ to $9.4 \%$ (39). Two such cases of a superficial ulnar artery have been identified in relation to the utilization of the free forearm flap $(40,41)$. Surgeons should be mindful when utilizing an extended carpal tunnel incision that reaches proximal to the wrist crease. Such an incision places a superficial ulnar artery at risk of injury

\section{MUSCLE ANATOMICAL VARIATIONS}

\section{Palmaris longus}

The classical report of Reimann et al (42) is the most comprehensive evaluation of anatomical variants of the palmaris 


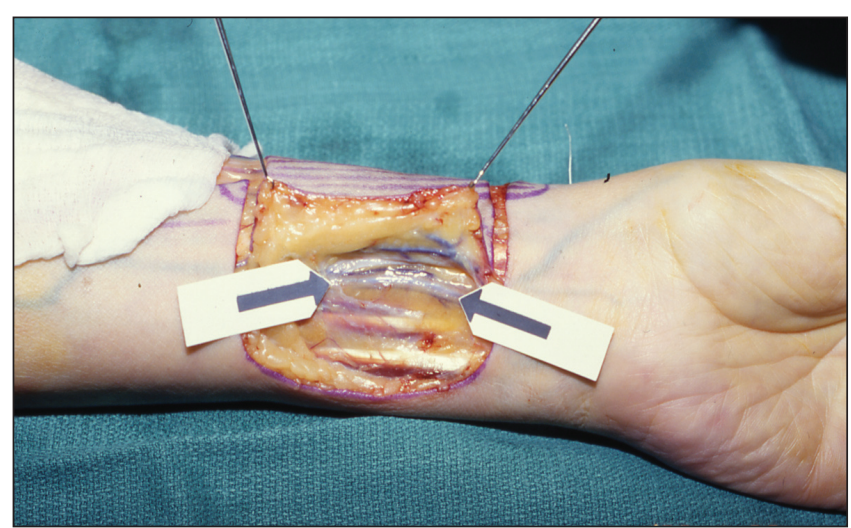

Figure 6) Superficial ulnar artery identified during forearm flap elevation, proximal to the carpal tunnel. The artery may be at risk in extended carpal tunnel release incisions or in repeat surgeries

longus muscle and its tendon. This study of 1600 cadaver extremities demonstrated that the palmaris longus is one of the most variable muscles in the human body, with a prevalence of morphological variation in $9 \%$ of subjects. Two variations of palmaris longus are of interest in carpal tunnel release. In the first, the palmaris longus tendon travels within the carpal tunnel and inserts distally into the palmar fascia (Figure 6). In the second variation, the muscle belly of the palmaris longus is located in the distal forearm and possibly within the carpal tunnel itself (Figure 7).

\section{Index lumbrical}

The index lumbrical muscle may originate proximally on the FDS within the carpal tunnel. Butler et al (43) presented a case report of this finding causing carpal tunnel compression syndrome (43). During the carpal tunnel release surgery, a tendinous slip was found adherent to the radial side of the median nerve. Backhouse and Churchill-Davidson (44) have also noted this anatomical variant, but did not comment on its relationship to carpal tunnel syndrome (44).

\section{FDS indicis}

Abnormalities of the FDS muscle have been described (45-49). In these reports, an anomalous muscle belly was found to extend into the carpal tunnel along the index finger tendon. In most cases, the patient's symptoms of carpal tunnel syndrome are thought to occur from muscular compression of the median nerve in a pistonlike fashion. The initial presentation of individuals with this anomaly is often swelling around the wrist or palm.

\section{DISCUSSION}

There are many anatomical variations in and around the carpal tunnel that affect the nerves, tendons and arteries in this area. Awareness of these variations is important both during the clinical examination and during carpal tunnel release. Preoperatively, the palpation of a pulse in the mid-line of the wrist may represent a persistent median artery or a superficial ulnar artery. The presence of symptoms that do not follow the classical distribution of the median and ulnar nerves in the hand should lead one to consider the presence of a Martin-Gruber anastomosis or Marinacci communication. A mass or lump detected within the transverse carpal ligament should

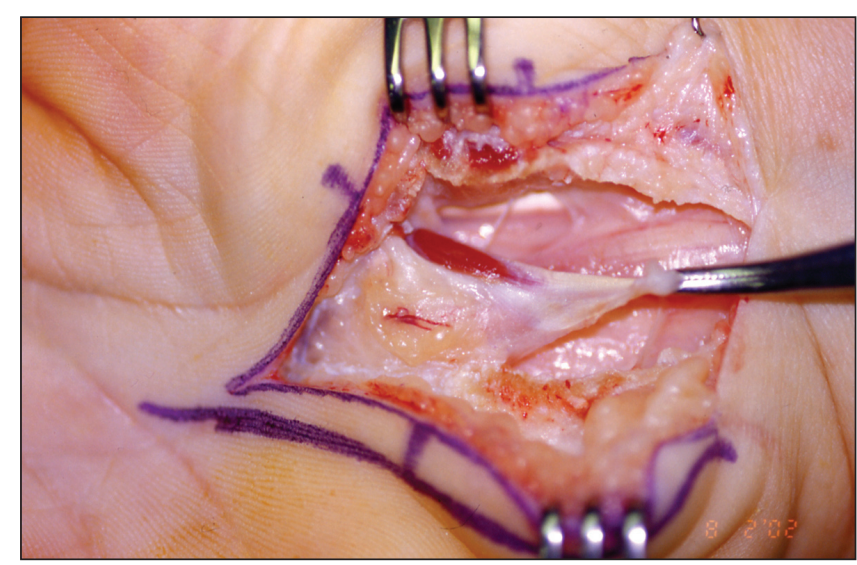

Figure 7) An anomalous palmaris longus muscle belly identified within the carpal tunnel, likely representing an accessory palmaris muscle

be examined with gliding of the fingers, as it may represent a proximal origin of the index lumbrical, or an anomalous muscle belly of the FDS to the indicis.

During carpal tunnel surgery, attention to anatomical variations is of obvious importance, particularly with respect to the palmar cutaneous nerve and the recurrent branch of the median nerve. Interestingly, considering the incidence of such variations, not many related complications have been reported during endoscopic carpal tunnel release, where many of the variations cannot be seen intraoperatively. Regardless of the approach to carpal tunnel release, it is imperative that plastic surgeons be cognizant of the above variations and be vigilant during carpal tunnel release.

DISCLOSURE: None of the authors have a financial interest in any of the products, devices, or drugs mentioned in this manuscript. No funding was provided for the preparation of this manuscript.

\section{REFERENCES}

1. Lindley SG, Jackson MS, Kleinert JM. Prevalence of anatomic variations encountered in elective tunnel release. J Hand Surg 2003;28A:849-55.

2. Lanz U. Anatomic variations of the median nerve in the carpal tunnel. J Hand Surg 1977;2A:44-53.

3. Amadio PC. Anatomic variations of the median nerve within the carpal tunnel. Clin Anat 1988;1:23-31.

4. Jeon IH, Kim PT, Park IH, Park BC, Ihn JC. High bifurcation of median nerve at the wrist causing common digital nerve injury in endoscopic carpal tunnel release. J Hand Surg 2002;27B:580-2.

5. Gutowski KA, Oliver WA, Mehrara BJ, Friedman DW. Arteriovenous malformation of a persistent median artery with a bifurcated median nerve. Plast Reconstr Surg 2000;106:1336-9.

6. Fernandez-Garcia S, Pi-Folguera J, Estallo-Matono F. Bifid median nerve compression due to a musculotendinous anomaly of FDS to the middle finger. J Hand Surg 1994;19B:616-7.

7. Szabo RM, Pettey J. Bilateral median nerve bifurcation with an accessory compartment within the carpal tunnel. J Hand Surg 1994;19B:1744-6.

8. Graham WP III. Variations of the motor branch of the median nerve at the wrist. Plast Reconstr Surg 1973;51:90-2.

9. Hurwitz PJ. Variations in the course of the thenar motor branch of the median nerve. J Hand Surg [Br] 1996;21:344-6.

10. Taleisnik J. The palmer cutaneous branch of the median nerve and the approach to carpal tunnel. An anatomical study. J Bone Joint Surg 1973;55A:1212-7. 
11. Papanastasiou S, Sood M. Aberrant position of the ulnar nerve within the carpal canal. Microsurgery 2004;24:24-5.

12. Eskesen V, Rosenorn J, Osgaard O. Atypical carpal tunnel syndrome with compression of the ulnar and median nerves. J Neurosurg 1981;54:668-9.

13. Galzio RJ, Magliani V, Lucantoni D, D'Arrigo C. Bilateral anomalous course of the ulnar nerve at the wrist causing ulnar and median nerve compression syndrome. J Neurosurg 1987;67:754-6.

14. Brandsma JW, Birke JA, Sims DS. The Martin-Gruber innervated hand. J Hand Surg 1986;11A:536-9.

15. Uchida Y, Sugioka Y. Electrodiagnosis of Martin-Gruber connection and its clinical importance in peripheral nerve surgery. J Hand Surg 1992;17A:54-9.

16. Leibovic SJ, Hastings H. Martin-Gruber revisited. J Hand Surg 1992;17A:47-53.

17. Nakashima T. An anatomical study of the Martin-Gruber anastomosis. Surg Radiol Anat 1993;15:193-5.

18. Taams KO. Martin-Gruber connections in South Africa. An anatomical study. J Hand Surg 1997;22B:328-30.

19. Shu H, Chantelot C, Oberlin C, Alnot JY, Shao H. Martin-Gruber communicating branch: Anatomical and histological study. Surg Radiol Anat 1999;21:115-8.

20. Simonetti S, Krarup C. Unusual ulnar sensory innervation and Martin-Gruber anastomosis in a patient with a carpal tunnel syndrome. J Neurol 2000;247:141-2.

21. Lee K, Oh C, Chung I, Sunwoo I. An anatomic study of the Martin-Gruber anastomosis: Electrodiagnostic implications. Muscle Nerve 2005;31:95-7.

22. Stancic MF, Burgic N, Micovic V. Marinacci communication. J Neurosurg 2000;92:860-2.

23. Kimura I, Ayyar DR, Lippmann SM. Electrophysiological verification of the ulnar to median nerve communications in the hand and forearm. Tohoku J Exp Med 1983;141:269-74.

24. Marinacci $\mathrm{A}$. The problem of unusual anomalous innervation of hand muscles: the value of electrodiagnosis in its evaluation. Bull Los Angeles Neruol Soc 1964;29:133-42.

25. Streib EW. Ulnar-to-median nerve anastomosis in the forearm: electromyographic studies. Neurology 1976;29:1534-7.

26. Mangini U. Flexor pollicis longus muscle: Its morphology and clinical significance. J Bone Joint Surg 1960;42A:467-70.

27. Linburg RM, Comstock BE. Anamalous tendon slips from the flexor pollicis longus to the flexor digitorum profundus. J Hand Surg 1979;4:79-83.

28. Rennie WR, Muller H. Linburg syndrome. Can J Surg 1998;41:306-8.

29. Stahl S, Stahl S, Calif E. Failure of flexor pollicis longus repair caused by anomalous flexor pollicis longus to index flexor digitorum profundus interconnections: A case report. J Hand Surg 2005;30A:483-6.

30. Takami H, Takahashi S, Ando M. The Linburg Comstock anomaly: A case report. J Hand Surg 1996;21A:251-2.

31. Lombardi RM, Wood MB, Linscheid RL. Symptomatic restrictive thumb-index flexor tenosynovitis: Incidence of musclotendionous anomalies and results of treatment. J Hand Surg 1988;13A:325-8.
32. Slater RR. Flexor tendon anomalies in a patient with carpal tunnel syndrome. J Hand Surg 2001;26B:373-6.

33. Bilgin SS, Olcay SE, Derincek A, Adiyaman S, Demirtas AM. Can simple release relieve symptoms of carpal tunnel syndrome caused by a persistent median artery? Arch Orthop Trauma Surg 2004;124:154-6.

34. Olave E, Prates JC, Gabrielli C, Pardi P. Median artery and superficial palmar branch of the radial artery in the carpal tunnel. Scand J Plast Reconstr Surg Hand Surg 1997;31:13-6.

35. Barfred T, Hojlund AP, Bertheussen K. Median artery in carpal tunnel syndrome. J Hand Surg [Am] 1985;10:864-7.

36. Kele H, Verhegen R, Reimers CD. Carpal tunnel syndrome caused by thrombosis of the median artery: the importance of highresolution ultrasonography for diagnosis. Case report. J Neurosurg 2002;97:471-3.

37. Gassner EM, Schocke M, Peer S, Schwabegger A, Jaschke W, Bodner G. Persistent median artery in the carpal tunnel: Color Doppler ultrasonographic findings. J Ultrashound Med 2002;21:455-61.

38. Zeiss J, Guilliam-Haidet L. MR demonstration of anomalous muscles about the volar aspect of the wrist and forearm. Clinical Imaging 1996;20:219-21.

39. Sieg P, Jacobsen HC, Hakim SG, Hermes D. Superficial ulnar artery: Course or blessing in harvesting fasciocutaneous forearm flaps. Head Neck 2006;28:447-52.

40. Thoma A, Young JE. The superficial ulnar artery "trap" and the free forearm flap. Ann Plast Surg 1992;28:370-2.

41. Fatah MF, Nancarrow JD, Murray DS. Raising the radial artery forearm flap: The superficial ulnar artery "trap." Br J Plast Surg 1985;38:394-5.

42. Reimann AF, Daseler EH, Anson BJ, Beaton LE. The palmaris longus muscle and tendon. A study of 1600 extremities. Anat Rec 1944;89:495-505.

43. Butler B, Bigley EC. Aberrant index lumbrical tendinous origin associated with carpal-tunnel syndrome. A case report. J Bone Joint Surg 1971;53A:160-2.

44. Blackhouse KM, Churchill-Davidson D. Anomalous palmaris longus muscle producing carpal tunnel-like compression. Hand $1975 ; 7: 22-4$.

45. Kono H. Acute carpal tunnel syndrome caused by anomalous muscle bellies: A case report. Hand Surg 2003;8:141-3.

46. Kostakoglu N, Borman H, Kecik A. Anomalous flexor digitorum superficialis muscle belly: An unusual case of mass in the palm. Br J Plast Surg 1997;50:654-6.

47. Ametewee K, Harris A, Samuel M. Acute carpal tunnel syndrome produced by anomalous flexor digitorum superficialis indicis muscle. J Hand Surg 1985;10:1:83-4.

48. Hutton P, Kernohan J, Birch R. An anomalous flexor digitorum superficialis indicis muscle presenting as carpal tunnel syndrome. Hand 1981;13:1:85-6.

49. Neviaser RJ. Flexor digitorum superficialis indicis and carpal tunnel syndrome. Hand 1974;6:155-6. 